\title{
NOVEL HYDROGEN GENERATOR/STORAGE BASED ON METAL HYDRIDES
}

\author{
C.M. RANGEL V. R. FERNANDES, Y. SLAVKOV, L. BOZUKOV \\ INETI, Electrochemistry of Materials Unit / DMTP, \\ Paço do Lumiar, 22 1649-038 Lisboa Portugal \\ Labtech Ltd. Mladost 1, Bld.25/A, Sofia 1784, Bulgaria \\ carmen.rangel@ineti.pt; vitor.fernandes@ineti.pt; \\ yslavkov@labtech.solo.bg; lbozukov@labtech.solo.bg
}

Key words: hydrogen generator/storage, metal hydrides, renewable hydrogen, stand-alone systems.

\begin{abstract}
A novel electrochemical system has been developed which integrates hydrogen production, storage and compression in only one device, at relatively low cost and high efficiency. The prototype comprises a six electrode cell assembly using an $\mathrm{AB}_{5}$ type metal hydride and $\mathrm{Ni}$ plates as counter electrodes, in a $\mathrm{KOH}$ solution. Metal hydride electrodes with chemical composition $\mathrm{LaNi}_{4 \cdot 3} \mathrm{Co}_{0.4} \mathrm{Al}_{0 \cdot 3}$ has been prepared by high frequency vacuum melting followed by high temperature annealing. X-Ray phase analysis showed typical hexagonal structure and no traces of other intermetallic compounds belonging to the La-Ni phase diagram. Thermodynamic study of the alloy has been performed in a Sieverts type apparatus produced by Labtech. Ltd. In the present prototype during charging, hydrogen is absorbed in the metal hydride and corresponding oxygen is conveyed out of the system. Conversely, in the case of discharging the hydrogen stored in the metal hydride it is released to an external $\mathrm{H}_{2}$ storage. Released hydrogen is delivered into the hydrogen storage up to a pressure of 15 bar. In this work, a compact unit integrating production, storage and compressing hydrogen is proposed as one device at relatively low cost and higher efficiency than a classical electrolyser. It is anticipated that the device will be integrated as a combined hydrogen generator in a stand alone system associated to a $1 \mathrm{~kW}$ fuel cell.
\end{abstract}

\section{Introduction}

The development of efficient, compact and reliable energy storage system based on hydrogen technology represents a challenge to seasonal storage based on renewable hydrogen that could be used in stand alone systems [1].

During the past decade the interest in such a systems has lead to the use of water electrolysis, introducing hydrogen as a long-term energy storage in order to match the primary available energy source to load demand, where previously batteries have been commonly used. The existing renewable energy generation systems include apart from the electrolyser, a hydrogen storage vessel and a fuel cell system for the conversion of $\mathrm{H}_{2}$ back into electricity when required.

In this work, a prototype developed as a compact unit is proposed as a novel electrochemical system which integrates hydrogen production, storage and compression in only one device. It has at relatively low cost and higher efficiency than a classical electrolyser. 


\section{Experimental and Results}

\subsection{Alloy synthesis and characterization}

The alloy with chemical composition $\mathrm{LaNi}_{4 \cdot 3} \mathrm{Co}_{0.4} \mathrm{Al}_{0 \cdot 3}$ has been prepared by high frequency vacuum melting of the metals with $99.5 \%$ purity. A high temperature annealing procedure at $1000^{\circ}$ $\mathrm{C}$ during 8 hours was applied after the melting process, in order to destroy the non-equilibrium microstructures as well as to reduce the stress and strain in the produced alloy.

Characterization of the alloy has been carried out by X-Ray phase analysis. The scattering curves were measured with a diffractometer Siemens D 500 (Ni-filtered $\mathrm{Cu}-\mathrm{K}_{\alpha}$ radiation) equipped with $\mathrm{LiF}$ monochromator. Rietveld program was used to make profile analyses and determination of the lattice constants of the alloys from the X-Ray powder diffraction data obtained.

The XRD study of the $\mathrm{LaNi}_{5}$ and $\mathrm{LaNi}_{4 \cdot 3} \mathrm{Co}_{0.4} \mathrm{Al}_{0 \cdot 3}$ alloys are presented on Figure 1 . The performed structural and phase analyses showed that it contains the typical for $\mathrm{AB}_{5}$ type alloys hexagonal $\mathrm{CaCu}_{5}$-structure and no any traces of other intermetallic compounds belonging to the La-Ni phase diagram. The only impurity phase $(\mathrm{Ni})$ has the estimated content of less than $0.5 \%$. The calculated lattice parameters for $\mathrm{LaNi}_{4 \cdot 3} \mathrm{Co}_{0.4} \mathrm{Al}_{0.3}(a=5.072 \AA, c=4.038 \AA, \mathrm{c} / \mathrm{a}=0.796)$ are similar to those for $\mathrm{LaNi}_{5}$ compound [2] and showing the slight expansion of the unit cell mainly in the basal plane.

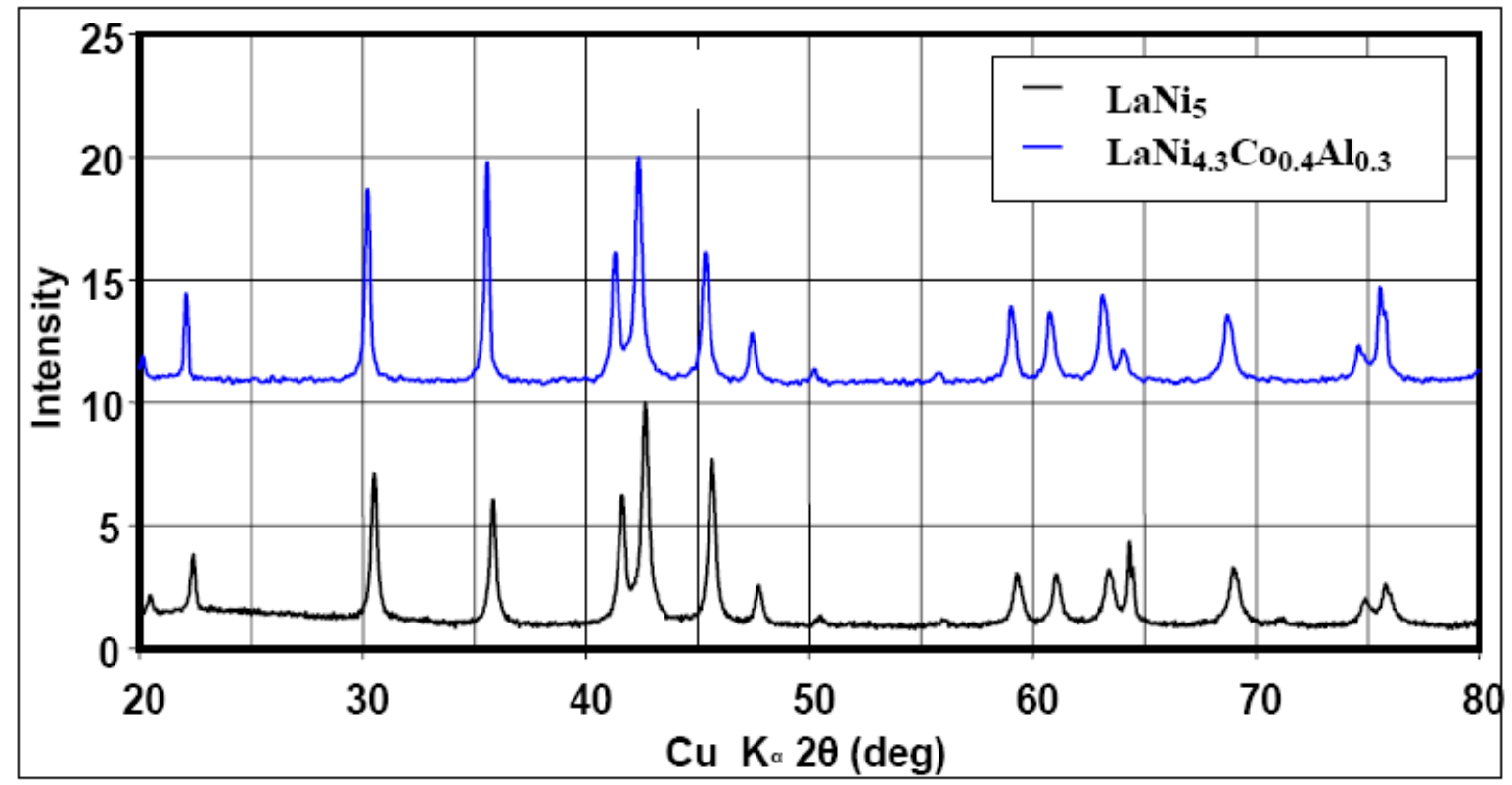

Figure 1. The XRD pattern of the $\mathrm{LaNi}_{4 \cdot 3} \mathrm{Co}_{0.4} \mathrm{Al}_{0 \cdot 3}$ alloy (Siemens D500, Cu-K $\mathrm{K}_{\alpha}$ )

A thermodynamic study of the alloys has been performed in a Sieverts type of apparatus (produced by Labtech. [3]) for investigation of hydrogen absorption/desorption properties. The PCT isotherms were measured at hydrogen pressure of 1-40 bars over the temperature range of $25-100^{\circ} \mathrm{C}$. Prior to the PCT measurements the samples were activated at hydrogen pressure of 25 bar and three absorption/desorption cycles performed.

The desorption PCT isotherms obtained from the gas phase with $\mathrm{LaNi}_{4 \cdot 3} \mathrm{Co}_{0.4} \mathrm{Al}_{0 \cdot 3}$ alloy composition at three different temperatures $\left(25^{\circ} \mathrm{C}, 40^{\circ} \mathrm{C}, 70^{\circ} \mathrm{C}\right.$ and $\left.100{ }^{\circ} \mathrm{C}\right)$ are presented in Figure 2. As it can be seen, the plateau pressure increases with concurrent temperature increase and the 
absorbed hydrogen amount decreases. The maximum amount of desorbed hydrogen is $160 \mathrm{~cm} 3 / \mathrm{g}$, which corresponds to a capacity more than $300 \mathrm{mAh} / \mathrm{g}$. This is close to the theoretically value calculated for a $\mathrm{LaNi}_{5} \mathrm{H}_{6}$ system [4].

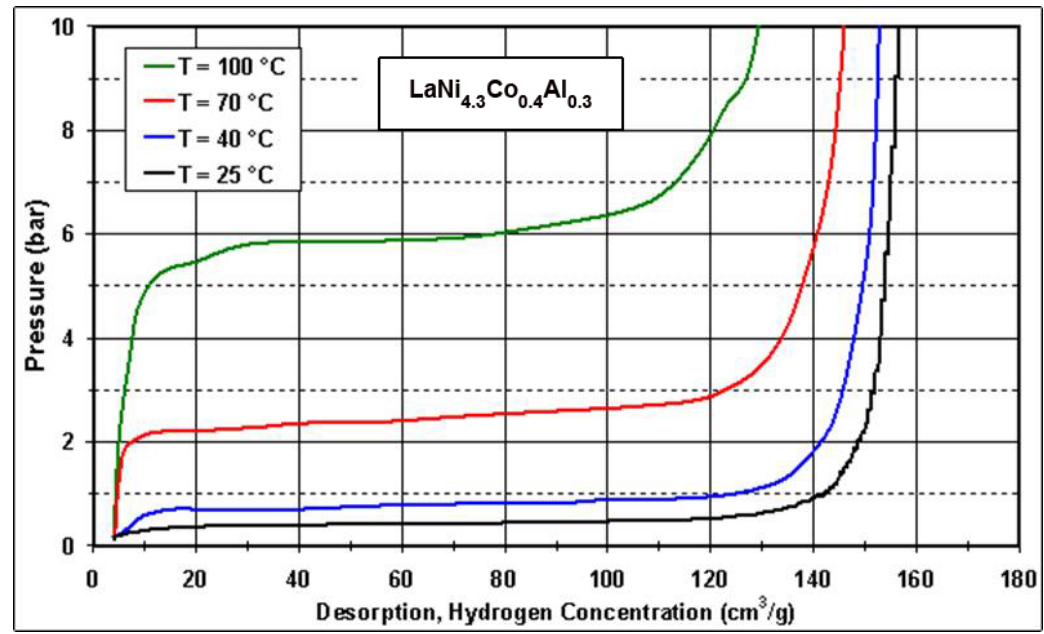

Figure 2. Desorption PCT isotherms of $\mathrm{LaNi}_{4 \cdot 3} \mathrm{Co}_{0.4} \mathrm{Al}_{0 \cdot 3}$ alloy used in the electrode assembly of the hydrogen generator/storage prototype proposed in this work.

\subsection{Monitoring prototype performance and efficiency}

The H-generator was developed as an electrochemical system and consists of a six cell assembly. Metal hydride electrodes and nickel plates as counter electrodes are installed in SS unit. A 35 wt\% $\mathrm{KOH}$ solution was used as electrolyte. The $\mathrm{MH}$ electrodes has been prepared using $\mathrm{LaNi}_{4 \cdot 3} \mathrm{Co}_{0.4} \mathrm{Al}_{0 \cdot 3}$ alloy with preparation method typical for $\mathrm{MH}-\mathrm{Ni}(\mathrm{OH})_{2}$ electrode for battery production [5]. A general view of the apparatus is shown in Figure 3.

During the electrochemical charging, hydrogen is absorbed in the metal hydride and corresponding oxygen is conveyed out of the system. Conversely, in the case of discharging the released hydrogen was delivered to the $\mathrm{H}$-storage with a pressure of $15 \mathrm{Bar}$, but the maximum $\mathrm{H}_{2}$ pressure depends of the mechanical construction of the whole system.

The gases releasing from the unit during charging/discharging processes were studied in-situ using an Agilent micro gas chromatograph, GC 300. The Micro GC is equipped with a Molecular Sieve $5 \mathrm{~A}$ column with argon as a carrier gas.

Initially some charging/discharging activation cycles were performed with metal hydride electrode consisting of $300 \mathrm{~g}$ metal hydride $\mathrm{LaNi}_{4 \cdot 3} \mathrm{Co}_{0.4} \mathrm{Al}_{0 \cdot 3}$ alloy. During cycling, the charging was run at $20 \mathrm{~A}$ at cell voltages of $1.6 \mathrm{~V}$ for 4 hours. Hydrogen was releasing by applying a constant current of $40 \mathrm{~A}$ for two hours until cell voltage rise from 0.5 to $0.8 \mathrm{~V}$, at the end of the processes.

It was found that during the 2 hours discharging process the whole hydrogen of 50 litters was desorbed from $\mathrm{MH}$ and no traces of oxygen were observed. The delivered hydrogen gas has high purity containing only some water vapour. 


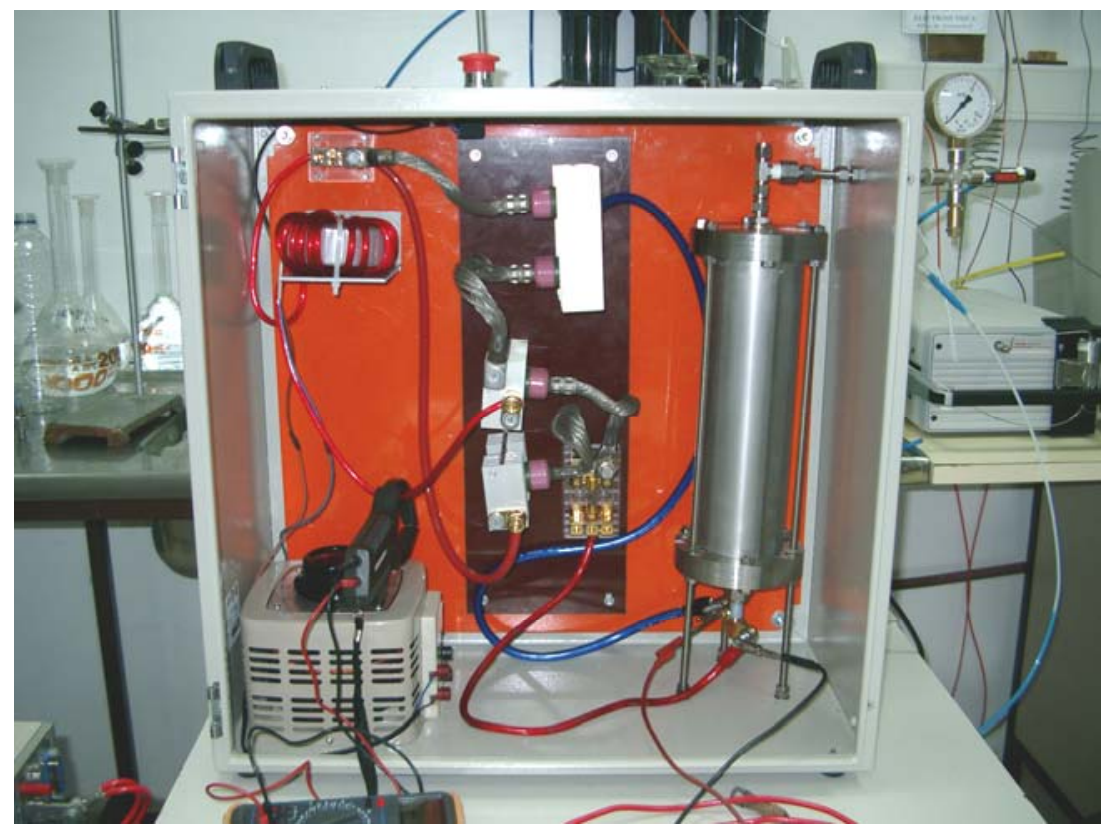

Figure 3. View of the H-Generator prototype integrating hydrogen generation and storage in a novel compact electrochemical system based on Metal Hydrides.

The theoretical efficiency of developed system could be quite high: about $3.3 \mathrm{~kW}$ per $1000 \mathrm{~L} \mathrm{H}_{2}$ production; this is based of the well known fact, that 1 gram metal hydride needs about $330 \mathrm{mAh}$ [6] to be charged electrochemically and under the assumption that the potential of the system is $1.4 \mathrm{~V}$.

However, during the charging, it was observed that a secondary process has taken place identified as water electrolysis. The result is additional amounts of hydrogen and oxygen released by the system, reducing the H-generator efficiency. These two processes observed were studied in-situ using a gas chromatograph from Agilent equipped with appropriate columns for the detection of $\mathrm{H}_{2}$, $\mathrm{O}_{2}$ and water content.

During the studies it was found that the ratio between the above processes has changed during charging time. The data obtained using gas chromatography is shown on figure 4.

The graphic presentation of the efficiency of the charging process of the developed H-Generator is presented on figure 5. It is clear that because of the mentioned secondary process, the efficiency of the whole system drops with time from 100 to $50-30 \%$ in the last $25 \%$ of charging time. It should be noticed that this efficiency did not depend on the charging current from 20-40A which corresponded to 4 to 2 hours charging time.

Even if the charging potential is relatively low for hydrolysis (1.6V), the process is found to take place being more remarkable with increasing of the concentration of the metal hydride phase in MHydride electrode. Our understanding of this fact is that metal hydride phase works as catalyst material, reducing the potential necessary for splitting of water. 


\section{Hydrogen flows during H-Generator charging process}

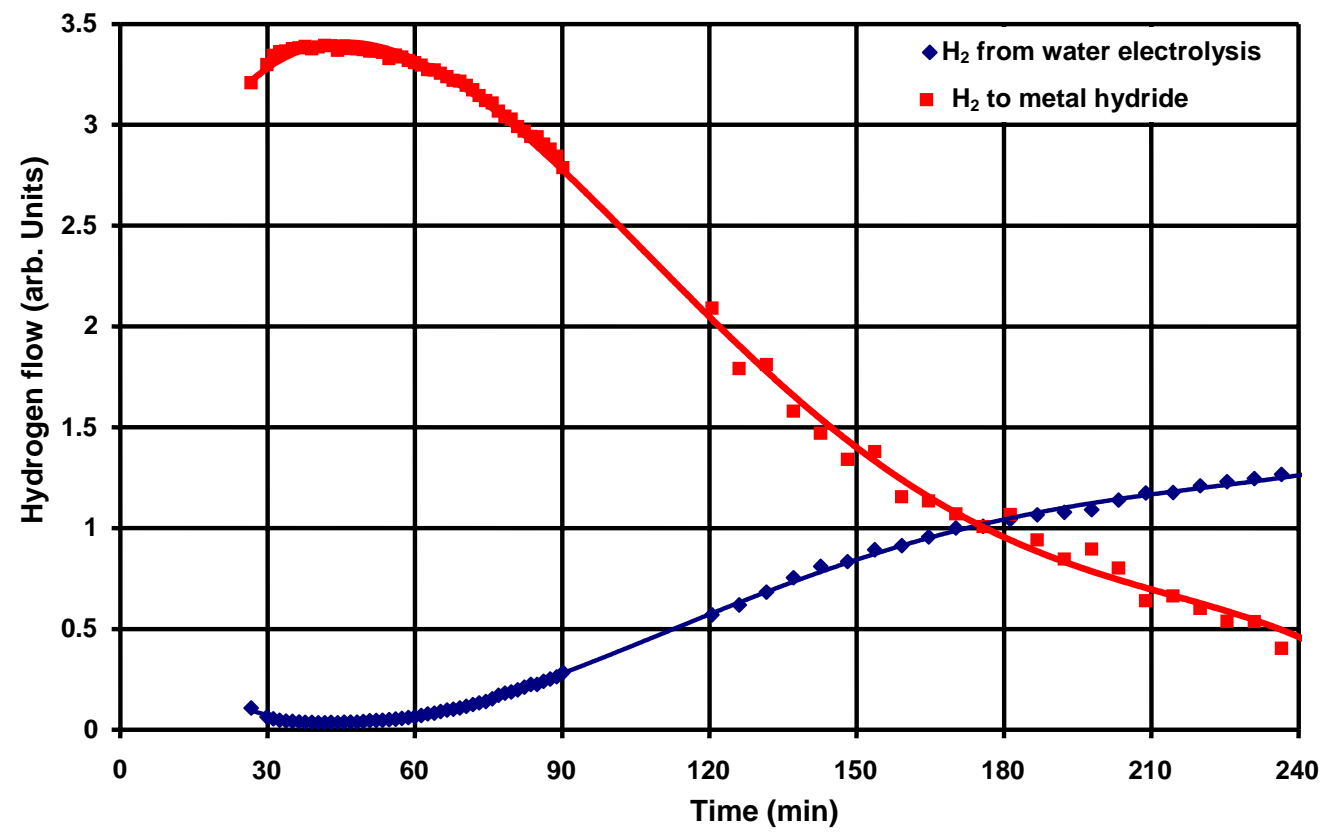

Figure 4. Hydrogen flow as a function of charging time of the H-Generator for two reactions: $(\square) \mathrm{H}_{2}$ to metal hydride; ( $\bullet) \mathrm{H}_{2}$ from water electrolysis.

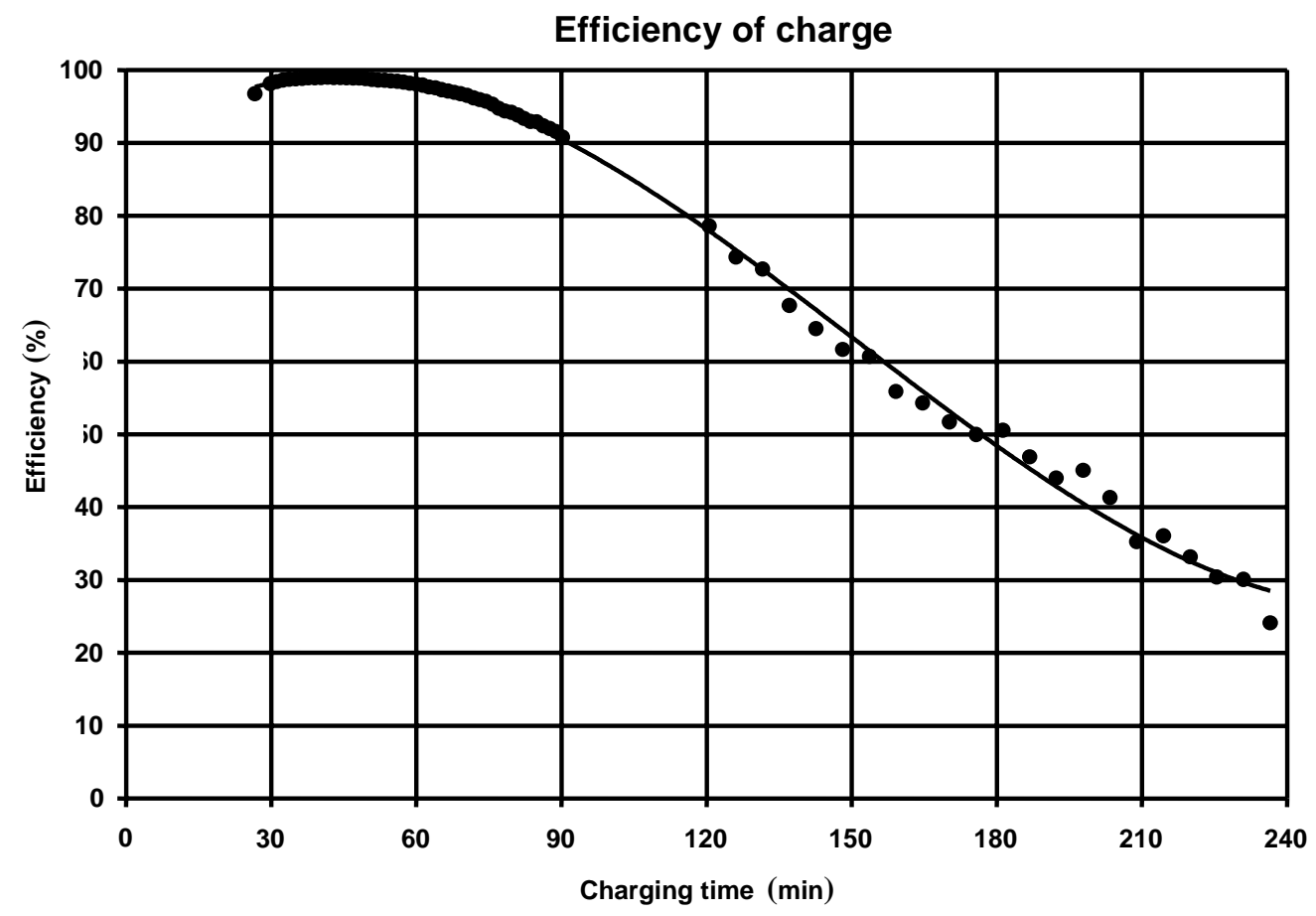

Figure 5. The efficiency of the charging process of the developed H-Generator. 


\section{Conclusions}

A novel device has been developed and studied. Results show the prototype H-Generator as a compact unit proposed as a novel electrochemical system which integrates hydrogen production, storage and compression in only one device.

Work in progress includes improving the process efficiency by decreasing the resistance between cell electrodes in the assembly.

It is anticipated that the device will be integrated as a combined hydrogen generator and storage unit in a stand alone system associated to a $1 \mathrm{~kW}$ fuel cell.

\section{References}

[1] E.I. Zolias, R. Glockner, N.Lymberopoulus, T.Tsoutsos, I. Vosseler, O.Galvalde, H.J. Mydske, P.Taylor, Ren. Sust. Energy Rev., 10 (2006) 432-462.

[2] K. H. J. Buschow and H. H. Van Mal, "Phase Relations and Hydrogen Absorption In the Lanthanum-Nickel System”, Journal of the Less Common Metals, Vol. 29, pp. 203-210, Elsevier Sequoia S. A.,Lausanne, Netherlands, 1972.

[3] L. Bozukov, A. Apostolov, T. Mudlarz, “Apparatus for in situ Measurements of Influence of Hydrogen Absorption on the Magnetic Properties of Intermetallic Compounds ” J. Magnetism and Magnetic Materials, 83 (1990) 555.

[4] M. Yamaguchi, E. Akiba, in: Buschov, K.H.J (Ed.), "Electronic and Magnetic Properties of Metals and Ceramics” Part II, VCH, Weinheim, 1994, p 334

[5] Labtech Ltd, “Metal Hydride Electrode for Alkaline Batteries” Patent BG 61984 B1, 30.04.1997

[6] T. Sakai, K. Guro, H. Miyamura, N.Kuriyama, A. Kato, H. Ishikawa, Ch. Iwakura,; "Some Factors Affecting the Cycle Lives of $\mathrm{LaNi}_{5}$-Based Alloy Electrodes of Hydrogen Batteries"; Journal of the Less-Common Metals, 161(1990) 193-202. 